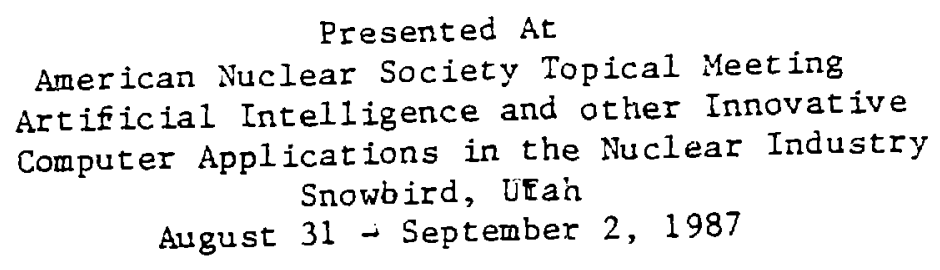

\section{An Expert System for Sensor Data Vulidation and Malfunction Detection}

\author{
Siavash Haghemit, Brian K Hajek, Don W. Miller \\ Nuclear Engineering Program \\ The Ohio State University \\ Columbur, Ohio $43210,37,2,5$
}

CONF-870832--8

DE88 004920

\title{
Introduction
}

Nuclear power plant operation and monitoring in general is a complex task which requires a large number of sensors, alarms and displays. At any instant in time, the operator is required to make a judgment about the state of the plant and to react accordingly. During abnormal situatione, operators are further burdened with time constraints. The possibility of an undetected faulty instrumentation line, adds to the complexity of operators' reasoning tasks.

Failure of human operators to cope with the conceptual complexity of abnormal situations often leads to more serious malfunctions and further damages to plarit (TMI-2 as an example). During these abnormalities, operators rely on the information provided by the planc sensors and associated alarms. Their usefulness however, is quickly diminished by their large number and the extremely difficult task of interpreting and comprehending the information provided by them. The need for an aid to assist the operatcr in interpreting the available data and diagnosis of problems is obvious.

Recent work at The Ohio State University Laboratory of Artificial Intelligence Research (IAJR) and the nwclear engineering program has concentrated on the problem of diagnostic expert gyatems performance and their applicability to the nuclear power plant domain. We have also been concerned about the diagnostic expert systems performance when using potentially invelid sensor data. Because of this research, we have developed an expert system that can perform diagnostic problem solving despite the existence of some conflicting data in the domain This work has resulted in enhancement of a programming tool, CSRL[1, 2], that allows domain experts to create a diagnostic aystem that will be to some degree, tolerant of bad data while performing diagnosis. This experi system is described here.

\section{Diugnosis in CSRL}

The developed expert system is capable of diagnosing the coolant system. malfunctions of a aimplified General Electric Boiling Water Reactor-6 (BWR/6) with Mark III containment. This model is developed by using Final Safety Analysis Report (FSAR) and other related doctuments of the Ferry Nuclear Power Plant, near Cleveland, Ohio.

1. Currently at IntelliCorp, MountainView, CA 
Problem solving in this domain has a ganoric character and typically has the task of classifying a given case into a diagrostic statement. In classification, the form of the required knowledge is of the form of a hierarchy of malfunition

hypotheses(3]. In this hierarchy of malfunctions, the top levels are more general diagnostic classes, and the bottom levelo correspand to morg apecifis cases (a type/subtype arrangement of the malfunctions). The set of the tip nodes in this hierarchy will then be thought of as the diagnostic conclusions relevant to the syistem.

The coolant system malfunctions are arranged in a claedsubclass hierarchicul malfunction tree (Fig. 1). Each node on this tree is called malfunction specialist and contain domain specific knowledge (or a knowledge base). Each specialist also contains information about how to utilize its knowledge base which is called the control knowledge.

Utilizing the above two sources of knowledge, diagnosis is performed on this malfunction hierarchy. The problem solving atrategy of this classification system is a top-down examination of the hierarchy, termed "Eatablish-Refine"[4].

Eatablish refine can be thought of as the examination of the "appropriateness" of a particular malfunction of the hierarchy. If that malfunction is found appropriate (i.e. Established), then its submalfunctions are also asked to establish (ie. Refine). If a specialint is not established, then none of its subnodes need be examined and that part $f$ the tree can bee pruned. Thus, the arrangement of the specialists on this hierarchical tree is of importance.

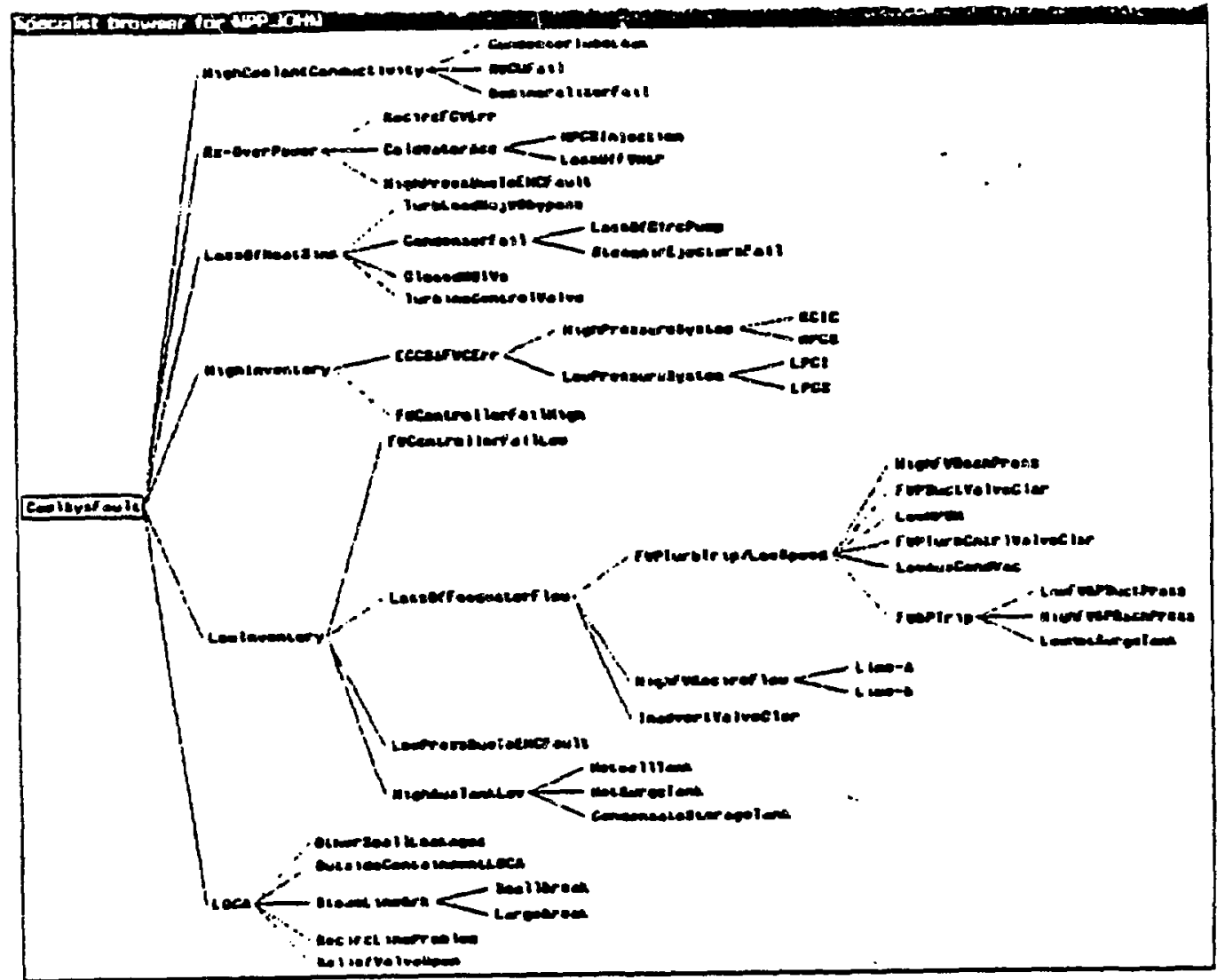




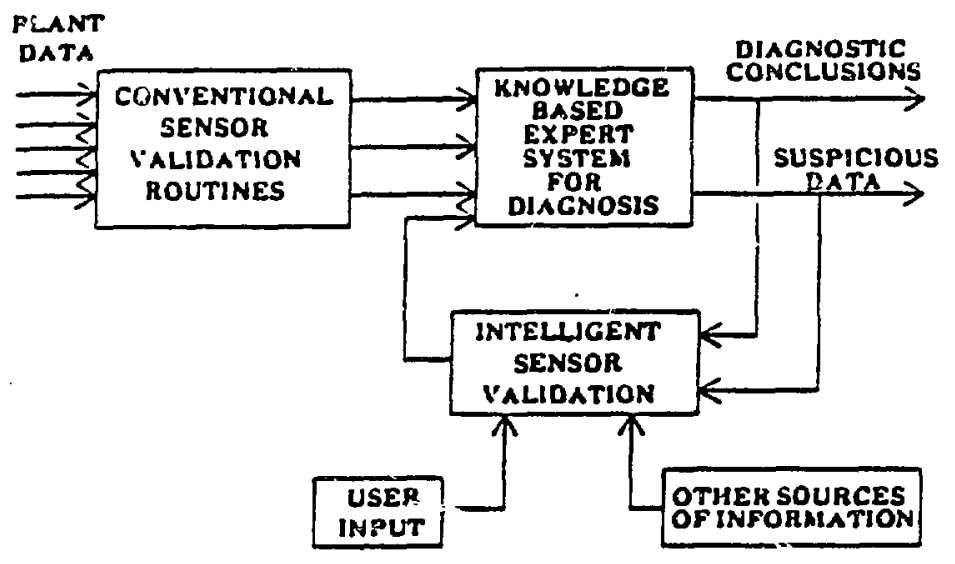

FIG 3. SENSOR VALIDATION ROLITIE BLOCX DLAGRAM

2. The second level of validation is beyond hardware redundancy and is accomplished through expectations derived during malfunction diagnosis. "That is, in the process of exploring the space of possible malfunctions, initial data and intermediate conclusions set up expectations of the characteristics of the final answer"[6]. This method of validation uses analytical redundancies and local verous system loop condition and is aimed at more subtle failures (such as instrumentation calibration drifto), and failures that are not detectable through the first etage of validation (euch as common cause failures). This technique is described below.

During the design stages of this ayatem, a great deal of attention was paid to ensure the syatem's ability of reaching diagnostic conclision based on partially complete data sets as well as potentially incorrect input parameters. To reach this goal, all relovant and useful sources of information for each malfunction hypothesis (specialist) were identified. Next, the relationahip betwoen them ure determined and proper combinations of this information are utilized in establinhing or rejecting the malfunction hypothesen. As an example, in order to detect a large Loss Of Coolant Accident (LOCA), the containment and the reactor pressure vessel parameters as well as the turbine-generator, suppression pool, main steam line and feedwater parameters are considered. In this fachion, having only a partial list of vulid parameters, a fairly accurate diegnoais is atill posoible.

One of the important factors to be noted here is that some combinations of the input date values can be marked as not capable of occurring or highly unlikely, due to violation of "normal expectations" of malfunctiona[6, 7]. That is, in the process of matching the malfunction patterms to data, certain combinations of data do not make sense in the given domain. As an example, turbine/generator electrical output must be zero (or decreasing rapidly), if the Main Steam Isolation Volves (MSIV8) are closed.

Thus, the process of faulty sensor identification involves three steps. These steps are:

1. The first step is to set some expectations by using local knowledge, or the context of other nodes.

2. The second step is to use these expectations to flag particular data values as questionable. And,

3. The third step is the process of validating (accepting) or rejecting the questionable sensor values based on the relational redundancies available in other parts of the plant. 
The evaluation of malfunction appropriateness is baced on knowledge embedded in each malfunction node of the hierarchy. In essence, each node ia capable of performing a simple kind of problem solving that evaluates whether the malfunction at this node exists, given the currently available data. This is accomplished by the knowledge groups of each node (Fig 2). Each knowledge group contain domain expertise in the form of, "what pattern of data must exist for this malfunction to be labeled appropriate? Furthermore, if the indicated pattern found, how must the appropriateness of the malfunction be modified?"

Appropriateness measure of each node is obtained by utilization of the confidence factors. These confidence fuctors range from -3 to +3 with significances ranging from "DEFINITELY NOT" to "DEFINITE", respectively. Confidence values are represented in the "VALUE" column of the Figure 2

Should the confidence value of a node be determinad as +2 or +3 , then the subnodes of that particular apecialist are also examined. If the node's confidence factor is determined to be between -1 to +1 , further anolygis of its subnodes are only posaible if further data be available, or no other conclusive diagnostic conclusion is obtained. If the connidence value of a node is -2 or -3 , the subnodes of that particular specialist are ignored until later steps into the diagnostic reasoning.

$U_{p}$ to this point, it has been assumed that the input data are 8 set of valid and reliable data. These input date are asaumed to have gone through the standard data validation routines (Fig. 3) and are in general, reliable. However, due to common cause failures, the input data may be faulty, and thus, some of the data may require further analysis. The past studies have also ohown that sensor duta validation and diagnosis are integral components to one another and one can not be accomplished without the other, in an efficient manner. Thus, sensor data validation is added to this expert system and is described next.

\section{Sensor Data Validation}

Sensor data validation can be thought of as a two stage function. Each stage is capable of identifying a certain class of faulty sensors. The two etages are as follows:

1. This stage of data validation which is mainly dependent on comparison of sedundant sensor signals (such as "like sensor"comparisons, fail safo assumptions, auctioneering, and 80 on) and is aimed at identificstion of gross failures of the instrumentation chennele (wuch as shorts, open circuits, connector or detector failuren). These techniques are based on various kinds of redundancy in sensor hardware and are discussed elsewhere[5].

\begin{tabular}{|c|c|c|c|c|c|}
\hline \multicolumn{6}{|c|}{$\begin{array}{l}\text { Expressions of } \\
\text { 1- (AskYNU? } \\
\text { 2- (AskHLN? } \\
\text { 3- (AskTrend? } \\
\text { 4- (AskliLN? }\end{array}$} \\
\hline 1 & $a$ & 3 & 1 & VALUE & SENSOR \\
\hline $\mathbf{T}$ & $($ Or Н HН) & $(\operatorname{or} I \mathrm{II})$ & (or H HA) & 3 & - \\
\hline$(\operatorname{or} P U)$ & (or H HH) & (ar $1 \mathrm{il})$ & (or H HK) & $9=$ & 1 \\
\hline (or FU) & $N$ & (er I II) & 7 & 10 & 14 \\
\hline$?$ & $?$ & 7 & 7 & -3 & - \\
\hline
\end{tabular}


The expectations derived during diagnosis are utilized as an extra source of redundancy, in addition to various conventional sensor hardware redundancies. These expectations are embodied in the specialists' knowledge groups and are formed and encoded a priori. The knowledge groups were then modified to check the malfunction pattern fit to the input data, and flag the parameters that lie outside the expectation as suspicious. The suppicious data are then subjected to further analyeis. This concept is demonatrated in the last column of Figure 2.

The knowledge group rows that do not meet the expected symptoms are identified as contsining suspicious data by addition of a "mon in their confidence values, as can be seen from Figure 2. Tha alarms the computer (and the user) that this row may contain invalid data and thus, the confiderice factor of this knowledge group may change as a result of sensor data validation.

Should a knowledge group row be identified as containing suspicious data, one of the following two cases must be valid:

- The set of expectations are not valid at that particular instant of time ieg. IF LARGE LOCA THE RPV WATER LEVEL =LOW is no longer valid if we are on the recovery path of a large LOCA).

- The set of symptoms are not valid at this particular instant of time which leads to the conciusion "THE XYZ (GROUP OF) SENSOR(S) HAVE FAILED".

In order to determine which one of the above situations is true, further analysis on the suspicious sensors is necessary. This analysis utilizes the following resources:

- Logical conclusions drawn fron diagnosis,

- Logical conclusione drawn from available data,

- Analytical calculations,

- Causal relationships between unlike parameters

These extra sources of information about the suspicious sensors are used to either validate or reject suspicious dato and are arranged in the order of preference for each individual sensor. In this fashion, the routines with minimum cost highest reliability, or minimum effort can be executed first, depending of each individual senaor. Note that this methodology is relying on unlike sensor data comparison and thus, common cause failures or ingtrumentation channel drifts are no longer problems.

One important fastor to avoid in this routine is that validation of one sensor should not rely on information supplied by another sensor which is also in the auspicious sensors liot. That is, one has to rely on the "potentially valid" data as redundancy, as opposed to "potentially faulty".

Once the faulty sensors are identified, there are two routes that can be taken:

1. Replace that faulty data with the new (and validuted) value and resume diagnosis after informing the user, or

2. Ignore that faulty data (mark it as Unknown) and resume diagnosis after informing the user.

These two methods muat lead to the same diagnostic conclusion (because a real plant can only have one state at a time). However, the first method is adapted for this project due to ease of implementation. 


\section{An Illustrating Example}

An inadvertent closure of the MSIV. (Closed MSIV malfunction node of Fig. 1) is considered as an example. If the MSTVs close, the Safety Relief Valves (SRVs) should cycle, in order to relieve and maintain pressure in the RPV. For this scenario, it is aeoumed that one of the SRVe fails to recloos after opening.

TO make this scenario more complicated for malfunction diasnoaim, it is also aseumed thet the direct indications of SRV and MSTV positions have failed and read CLOSED and OPEN, reapectively. That is, the control board lights do not change status from their pre-event indications.

During the first run of the liagnostic aystem, the LOCA node has fired with a confidence factor of 0 * to shuw more evidence is required to either establish or reject the LOCA possibility. Further up in the tree, the ClosedMSIYg and TurbineControlvalve nodes fire with confidence factors of $0^{\circ}$ and $3^{\circ}$, respectively. This means that there is a mild indication of MSIV closure and therefore, a strong ovidence for the wrong turbine control valve position.

During the sensor signal validation stop, the list of auspicious data is inspected and validated. Backup information for the SRV position is obtained from the local suppression pool temperature profile and SRV-downcommer pressure (Perry specific). The backup information for the MSIV position was obtained from matching the steum flow rate, RPV pressure and turbine electrical output.

After validation of the suspicious data, the new values sro replaced in the database and new diagnosis indicated the correct state of the plant [Fig 4]. The new confidence factors indicate that no more suspicious dsta exists.

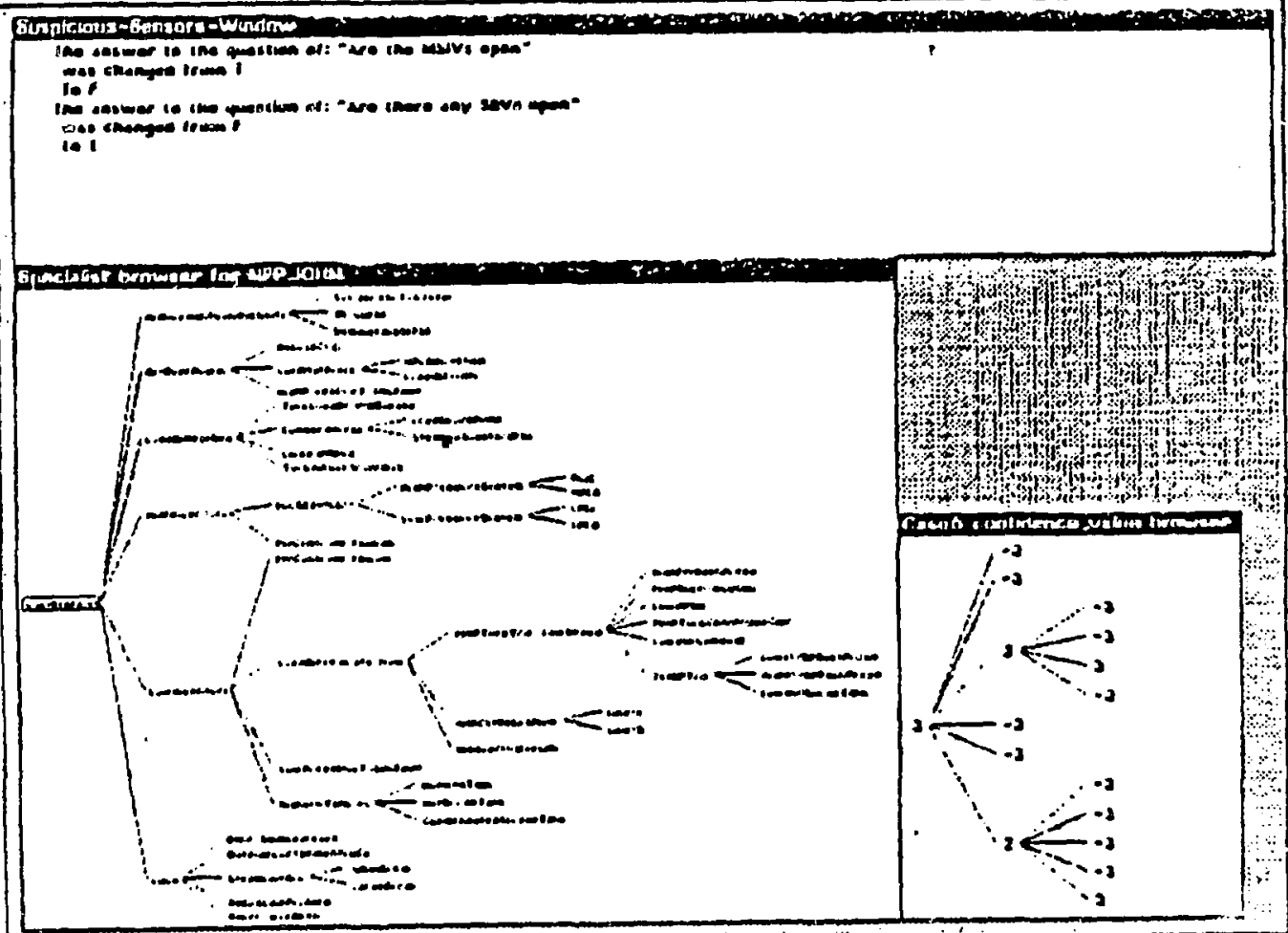




\section{Conclupions}

This expert aystem is capeble of performing disgnosis and sensor data validation, in an efficient manner. This expert aystem is tolerant to faulty input parameters to a certain extent and provides an additionai sensor validation routines to the nuclear power plant personnel.

\section{Acknowlodgrments}

The authors wish to acknowledge Professor B. Chandrasekaran for his insights and assistance in developing these ideas. We would like to also acknowledge Mr. John Stasenko for his atcempts to expand the knowledge base of this expert system. This work was supported in parts by NSF, DOE, and internal grants.

\section{References}

1. T. Bylander, S. Mittal, B. Chandrasekaran, "CSRL: A Language for Expert Systems for Diagnosis", Proc. of IJCAI 83,.Los Altos, CA, PP 218-21.

2. B. Chandrasekaran, "Decomposition of Domain Expert Knowledge into Knowledge Sources: the MDX Approach", Proc 4th Nationsl CSCSISCEIO, Sakatoon, Canada, May, 1982.

3. B.K Hajek, S. Hashemi, D.D. Sharma, B. Chandrasekaran, D.W. Miller, Artificial Intelligence Enhancement to Safety Parameter Display Systems". Proc. 6th Power Plant Dymamic8, Control and Teating Symposium, Knorville, Tenn, April, 1986.

4. B. Chandrasekaran. "Towards Taxonomy of Problem Solving Types", AI Magazine, Vol 4, No. 1, Winter/Spring 1983. J.J. Deysh KM. Kanazawa, J.P. Pasquen2a, "Sensor Validation: A Method to Enhance the Quality of ManMachine Interface in Nuclear Power Stations", IEEE Transactions on NS, Vol NS-28, No. 1, Feb. 1981.

5. B. Chandrasekaran, W.F. Punch, "Data Validation During Diagnasis, a Step Deyond Traditionul Sensor Validation", Proc. AAAI, Seattle, WA, 1987.

6. B. Chandrasekaran, W.F. Punch, "Hierarchical Claseification: Its Usefulnesa for Diagnosis and Sonsor Validation", Proc 2nd AJAANASAUSAF Symposium on Automation, Robotice, and Advanced Computing, Fob 1987.

\section{DISCLAIMER}

This report was prepared as an account of work sponsored by an agency of the United States Government. Neither the United States Government nor any agency thereof, nor any of their employees, makes any warranty, express or implied, or assumes any legal liability or responsi bility for the accuracy, completeness, or usefulness of any information, apparatus, product, or process disclosed, or represents that its use would not infringe privately owned rights. Reference herein to any specific commercial product, process, or service by trade name, trademark. manufacturer, or otherwise does not necessarily constitute or imply its endorsement, rexommendation, or favoring by the United States Government or any agency thereof. The views and opinions of authors expressed herein do not necessarily state or reflect those of the United States Government or any agency thereof 